\title{
Host-Virus Specificity of the Morbillivirus Receptor, SLAM, in Marine Mammals: Risk Assessment of Infection Based on Three-Dimensional Models
}

\author{
Kazue Ohishi, Rintaro Suzuki and Tadashi Maruyama
}

Additional information is available at the end of the chapter

http://dx.doi.org/10.5772/53215

\section{Introduction}

Incidences of infectious diseases in marine mammals have been increasing [1]. Among them, morbillivirus infection is the greatest threat to marine mammals becuase it has caused mass die-offs in several pinniped and cetacean species in the past few decades $[2,3]$. The genus Morbillivirus belongs to the family Paramyxoviridae, and the viruses in this genus have a genome consisting of a single piece of negative-stranded RNA, which encodes eight viral proteins: a nucleocapsid protein $(\mathrm{N})$; a phosphoprotein $(\mathrm{P})$; two virulence factors $(\mathrm{C}$ and $\mathrm{V})$; a matrix protein $(\mathrm{M})$; a membrane fusion protein $(\mathrm{F})$; a hemagglutinin binding protein $(\mathrm{H})$; and an RNA polymerase (L) [4]. The two viral surface glycoproteins, $\mathrm{H}$ and $\mathrm{F}$, play important roles during the viral infection of host cells. The $\mathrm{H}$ protein is required for viral attachment to the host cells, while the F protein mediates membrane fusion with the host plasma membrane and enables the entry of the virus.

Until the discovery of a new mobillivirus in marine mammals in 1988, only four morbillivirus species had been identified in land mammals: the measles virus (MV); rinderpest virus (RPV); peste des petits ruminants virus (PPRV); and canine distemper virus (CDV) [4]. The new morbillivirus was isolated from dead harbor seals (Phoca vitulina) in a mass die-off around the Baltic and North Sea coasts and was named phocine distemper virus (PDV) $[5,6]$. Two other new viruses originating in cetaceans were also isolated from dead harbor porpoises (Phocoena phocoena) and striped dolphins (Stenella coeruleoalba) and were named porpoise morbillivirus (PMV) and dolphin morbillivirus (DMV) [7,8]. Based on the similarities of the gene sequences, it was proposed that the cetacean-origin viruses be unified as a single species, cetacean morbillivirus (CMV) $[9,10]$. 
Morbilliviruses propagate primarily in lymphoid tissues and induce acute disease. They are usually accompanied by lymphopenia and immunosuppression, which often lead to secondary, opportunistic infections in the host. The distemper viruses, CDV and PDV, often invade the central nervous systems of their hosts, although acute encephalitis is not common in other morbillivirus infections [4]. A notable feature of morbilliviruses is their high host specificity. The natural host of MV is humans, but it can also infect monkeys. Ruminants are the targets of RPV and PPRV. RPV mainly infects cattle, while PPRV infects goats and sheep. Although these viruses have multiple host compatibilities, they induce more severe disease in the primary hosts than in others [11,12]. The natural host for CDV is dogs, but ferrets (Mustela putorius furo) have been used as an experimental model due to their high sensitivity to CDV. Recently, the host range of CDV has been shown to be wider than previously thought and expanded to include other wild carnivores, such as Baikal seals (Phoca sibirica) or lions (Panthera leo) [13-15]. PDV and CMV have been isolated only from seals and cetaceans, respectively. While no morbilliviruses have been isolated from sirenians, serologic evidence of exposure to morbillivirus was reported in manatees (Trichechus manatus) without showing clinical signs of disease [16,17].

The cellular receptor of a virus is one of the major determinants of host specificity and tissue tropism. The signaling lymphocyte activation molecule (SLAM) has recently been shown to be the principal cellular receptor for morbilliviruses in humans, cows, and dogs $[18,19]$. SLAM itself was first discovered in 1995 as a novel receptor molecule involved in T-cell activation [20]. It is expressed on various immune cells, such as thymocytes, activated $\mathrm{T}$ and B cells, mature dendritic cells, macrophages, and platelets [21,22]. SLAM is also a marker for the most primitive hematopoetic stem cells [23]. The distribution and function of SLAM are consistent with the cell tropism and immunosuppressive nature of morbilliviruses. This indicates that the host range of morbillivirus may be explained by key amino acid residues of SLAM on the interface with morbillivirus.

In this chapter, we review morbillivirus infection in marine mammals and its possible primary receptor in the host, SLAM. Further, we discuss host-virus specificities based on three-dimensional models of SLAM and risk assessment of morbillivirus infection in marine mammals.

\section{Morbillivirus infection and its impact on marine mammals}

\subsection{Mass die-offs in marine mammals and discovery of new morbilliviruses}

Since the late 1980s, many mass die-offs have been reported around the coasts of Europe and the USA (Table 1). Approximately 18,000 harbor seals and several hundred grey seals (Halichoerus grypus) were found dead on northern European coasts in 1988-1989. The distemper-like gross observations suggested that a morbillivirus could have been the causative agent [6]. Detailed serological, virological, and immunohistochemical examinations showed that the agent was a new member of the genus Morbillivirus, named phocine distemper virus (PDV) [5,24]. In 2002, PDV again killed at least 21,000 seals 
inhabiting the same locales $[25,26]$. About the same time as the first outbreak on northern European coasts, in 1987-1988 the deaths of approximately 18,000 Baikal seals were reported in Lake Baikal which showed clinical signs identical to those reported in European seals [13]. However, subsequent genomic characterization revealed that the cause of the mass dieoff of Baikal seals was CDV [27-31]. CDV also induced another mass die-off among Caspian seals (Phoca caspica), in which many seals died in 1997 and 2000, near Azerbaijan on the western shores of the Caspian Sea [32,33].

\begin{tabular}{ccccc}
\hline Date & Site & Animal species & No. of dead & Virus \\
\hline $1987-1988$ & USA Atlantic coast & Tursiops truncatus & $>2,500$ & CMV \\
$1987-1988$ & Lake Baikal & Phoca sibirica & $>18,000$ & CDV \\
1988 & North \& Baltic Sea & Phoca vitulina & $>18,000$ & PDV \\
1990 & Mediterrean Sea & Stenella coeruleoalba & $>2,000$ & CMV \\
1993 & Mexican Gulf & Tursiops truncatus & $>1,000$ & CMV \\
1997 & Caspian Sea & Phoca caspica & $>2,000$ & CDV \\
2000 & Caspian Sea & Phoca caspica & $>10,000$ & CDV \\
2002 & North \& Baltic Sea & Phoca vitulina & $>21,000$ & PDV \\
\hline
\end{tabular}

CMV, cetacean morbillivirus; CDV, canine distemper virus; PDV, phocine distemper virus.

Table 1. Mass die-offs of marine mammals caused by morbilliviruses.

The first evidence of morbillivirus infection in cetaceans was described in several stranded harbor porpoises with pathological changes on the Irish coastline in 1988 [7]. A new morbillivirus was isolated and termed PMV for "porpoise" [34]. Since 1990, a severe mass die-off began to affect the striped dolphin (Stenella coeruleoalba) population on the Mediterranean coast of Spain and rapidly spread throughout the western Mediterranean Sea, including the coasts of France, Italy, Greece, and Turkey [8,35] (Table 1). A new virus, named DMV for "dolphin" was isolated as the causative agent [9]. A retrospective serologic investigation indicated that PMV and DMV were the agents responsible for another epidemic in bottlenose dolphins (Tursiops truncatus) along the Atlantic coast of the USA, for which the causative agent had been initially thought to be brevetoxin produced by a marine dinoflagellate (Ptychodiscus brevis) [36-38]. PMV also induced a die-off of bottlenose dolphins in the Gulf of Mexico during 1993-1994 [37-39]. Molecular biological analyses of these cetacean morbilliviruses showed that their gene sequences were similar $[9,10]$. Based on the similarities, it was proposed that these cetacean morbilliviruses be classified as a single species called CMV.

Thus, morbillivirus infection has a strong impact on populations of marine mammals, as listed in Table 1. In addition to mass die-offs, many smaller-scale die-offs were reported in various oceans. Even if the scale is small, outbreaks of morbillivirus infection can have serious consequences for marine mammal populations, especially among endangered species at risk of extinction, such as Mediterranean monk seals (Monachus monachus). In 1997, approximately $50 \%$ of the population of Mediterranean monk seals residing along the 
coast of Mauritania in Africa died suddenly. Morbilliviruses were isolated from the dead seals, although distemper-like lesions were not detected in the animals [40]. Hence, it remains unclear whether morbillivirus was the agent responsible for the dramatic deaths. The involvement of an algal bloom was also suggested as the primary cause [41]. In any case, when populations of many marine mammal species are decreasing, morbillivirus infection may cause a fatal blow.

\subsection{Transmission and maintenance reservoir of marine morbilliviruses}

The origin, precise mode of transmission, and maintenance reservoir of morbilliviruses causing die-off epidemics in marine mammals remain to be elucidated. Morbilliviruses proliferate in the infected animal for a short time after infection but do not persist in the host [4]. After being shed from the infected host, they do not survive long in the environment [4]. For the transmission of morbilliviruses, therefore, close contact between acutely infected and susceptible animals is required. In addition, because a morbillivirus infection results in lifelong immunity in the infected animal, when the virus is maintained in an animal population, a constant supply of new susceptible animals is needed. It has been calculated that the minimal population size for MV maintenance is approximately 300,000 individuals [42]. In the mass die-off of European seals in 1988, the most likely viral source was an infected seal population in the Arctic region, which moved southward and made contact with the population on the European coast. This hypothesis was based on the results of serologic studies using archival seal sera. PDV-specific antibodies were not observed in European seal sera before 1988, indicating that the population was naive and had not been previously exposed to the virus [43]. However, specific antibodies were detected in sera obtained from arctic seals long before 1998 [44,45]. In addition, alterations in the migration patterns of Arctic harp seal (Phoca groenlandica) populations were recorded. They were seen much farther south than usual in northern European waters in the year prior to the epizootic of the harp seal population [46]. The harp seal population is extremely large, with four million individuals in Canadian waters alone, which is sufficient to maintain morbillivirus circulating within the population. Subclinically or subacutely affected animals might play an important role in the transmission of the virus.

It should be noted that morbillivirus transmission sometimes occurs between marine and land mammals. As described above, the mass die-offs of Baikal seals and Caspian seals were caused by infection with CDV [28,30,32]. The most likely source of infection was land animals infected with CDV, because outbreaks were common among the numerous feral and domestic dogs around the lake [47]. Accidental infection in the opposite direction was also reported. A farmed mink population fed infected seal meat was infected with PDV in Denmark during the 1988 epizootic of PDV [48].

\section{SLAM, a receptor of morbillivirus}

The characteristics of SLAM have been extensively studied in humans. SLAM (CD150) is a type I transmembrane protein, and there are many members of the SLAM family including 
the well-known 2B4 (CD244), Ly-9 (CD229), NTB-A, and CD84 [49]. All of the SLAM family members have an extracellular region composed of a membrane-distal immunoglobulin variable (V) domain and a membrane-proximal immunoglobulin constant-2 (C2) domain, along with a cytoplasmic region bearing multiple tyrosine-based switch motifs (ITSMs) that bind cytoplasmic Src homology-2 (SH2)-containing proteins such as SLAM-associated protein (SAP) [50]. Evidence is accumulating that the interaction between the cytoplasmic region of SLAM and SAP family molecules mediates a switch to positive or negative signaling in immune cells and plays a crucial role in multiple immune regulations [22]. Genes for the SLAM family receptors are located within a $\sim 400-\mathrm{kb}$ cluster on chromosome 1 in humans and mice [51]. This gene location, coupled with the conserved exon-intron structure of SLAM-related genes, implies that they were generated by the sequential duplication of a single ancestral gene. A SLAM family receptor forms a homophilic dimer by weak binding between the $\mathrm{V}$ domains and acts as a self-ligand, suggesting that the receptors can trigger homotypic or heterotypic cell-cell interactions [52]. The V domain of SLAM (CD150) also provides an interface for binding with morbilliviruses [53]. The viral $\mathrm{H}$ protein has a strong affinity for the V domain of SLAM, which is 400-fold higher than for self-ligand interaction [54]. The interaction between the viral $\mathrm{H}$ protein and SLAM V domain is the initial event in infection with morbilliviruses. The results of recent detailed structural studies have suggested that the interaction changes the microenvironment of the interaction zone for the fusion activity of the F protein, although the mechanism of membrane fusion mediated by the F protein is not fully understood [55-58].

\subsection{History of the discovery of the morbillivirus receptor}

The human CD46 molecule was first identified as a cellular receptor for Edmonston vaccine strains of MV [59,60]. The Edmonston strain was isolated from the blood and throat washings of a child with measles using primary human kidney cells in 1954 [61]. It was later adapted to chick embryo fibroblasts and is being used as an attenuated vaccine [62]. This strain grows well in many cell lines, such as Vero cells, and has become the most extensively studied MV strain in the laboratory. However, because CD46, a complement-regulatory molecule, is expressed on all human nucleated cells, its ubiquitous distribution cannot explain the lymphoid tropism of MV. At present, CD46 is thought to be a specific receptor of the Edmonston strain, which is presumed to acquire the ability to use CD46 by adapting to cultured human kidney cells.

On the other hand, many wild-type strains have been isolated from clinical samples using the marmoset B cell line (B95a) [63], but they do not grow on many CD46+ cell lines. In order to identify the receptor for wild-type MV, functional expression cloning of a cDNA library of B95a cells was carried out using the VSV pseudotype system. SLAM was shown to be a cellular receptor for wild-type MV [18]. CDV and RPV were also shown to use canine and bovine SLAMs for entry into host cells [19]. Thus, SLAM is thought to be the major receptor for wild-type morbillviruses.

Recently, Nectin 4, a cellular adhesion junction molecule, has been identified as the third receptor for MV in polarized epithelial cells [64,65]. Infection experiments in monkeys 
showed that MV initially targets SLAM-positive immune cells such as alveolar macrophages, dendritic cells, and lymphocytes, and later the viral infection spreads to the epithelial cells of the trachea, lungs, oral cavity, pharynx, or intestines, which are SLAMnegative cells [66,67]. Another infection experiment using epithelial cell receptor-blind MV, demonstrated that the mutant MV inoculated intranasally to monkeys shows virulence and infectivity toward lymphoid tissues, although the virus cannot cross the airway epithelium and cannot be shed in the air [68]. The molecule forms tight junctions on polarized epithelial cells and was shown to function as the receptor for effectively releasing MV to the apical side of epithelial cells $[69,70]$. This explains why MV is highly contagious. Thus, the wildtype MV posesses two types of receptor, SLAM for entry and propagation and Nectin 4 for viral release into the air.

\subsection{Structure of SLAMs of marine mammals}

Cetaceans and sirenians have achieved complete adaptation to the aquatic environment and spend all of their lives in water. Cetaceans belong to the order Cetartiodactyla, superorder Laurasiatheria, and are closely related to hippopotami or ruminants among land animals. Sirenians, including dugongs and manatees, are in the order Sirenia, superorder Afrotheria, and are evolutionarily related to elephants or hyraxes. Pinnipeds, belonging to the order Carnivora, superorder Laurasiatheria, are not completely adapted to the aquatic environment and they must deliver and nurse their young on land. This characteristic of pinnipeds makes it possible to transmit infectious diseases between aquatic and land mammals. To determine the structure of marine mammal SLAMs, we collected blood samples from taxonomically different animal groups, i.e., cetaceans, pinnipeds, and sirenians. White blood cells were obtained from: two species of cetacean, a Pacific white-sided dolphin (Lagenorhynchus obliquidens) and a killer whale (Orcinus orca); two species of pinniped, a spotted seal (Phoca largha), and a walrus (Odobenus rosmarus); and a sirenian, a West Indian manatee (Trichechus manatus). The blood of an Indian elephant (Elephas maximus bengalensis) was also collected. After immune stimulation with phytohemagglutinin, RNAs of the leukocytes were extracted. First, the complete nucleotide sequences of the SLAM genes were determined. Three-dimensional models were then generated based on the deduced amino acid sequences to compare the interface of their SLAM V domains [71].

\subsubsection{Primary structure of SLAM proteins}

The deduced amino acid sequences of marine mammal and elephant SLAMs indicated that they contain 336-339 amino acid residues, inducing six cysteine residues and six potential $N$-linked glycosylation sites (Figure 1). They have two immunoglobulin-like domains, $\mathrm{V}$ and $\mathrm{C} 2$, in the extracellular region, and two ITSM motifs (T-X-Y-X-X-V/I) and one ITSM-like sequence in the intracellular region. These molecular features are shared with all reported mammalian SLAMs (Figure 1). The cetacean and pinniped SLAMs showed the greatest homology with those of artiodactyla (cow and sheep, $84-85 \%$ identity at the amino acid level) and of dogs (84\%), respectively. Manatee SLAM shared the greatest homology with that of the elephant (86\%) [71]. 
(a)

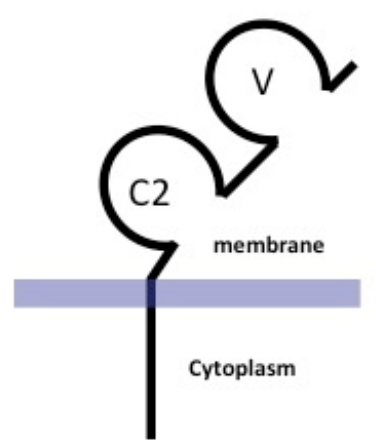

(b)

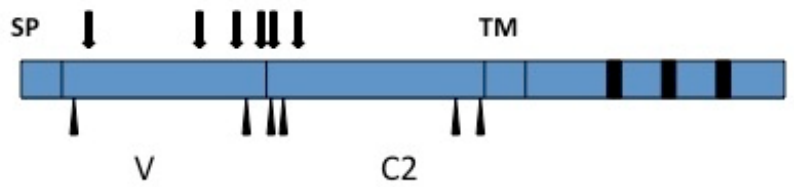

SP: signal peptide, TM: transmembrane region, V: immunoglobulin V-like domain, C2: immunoglobulin C2-like domain. Closed squares: ITSM and ITSM-like motifs, The $N$-linked glycosylation site and cysteine residues are indicated by arrows and triangles, respectively.

Figure 1. Schematic drawings of domain (a) and primary structure (b) of marine mammal SLAMs.

\subsubsection{Phylogenetic analysis based on SLAM and morbillivirus H proteins}

Phylogenetic trees based on SLAM and the morbillivirus $\mathrm{H}$ protein were constructed using the maximum-likelihood (ML) and Bayesian methods. In the phylogeny of SLAMs (Figure 2(a)), each taxonomic group, including primates (humans, chimpanzees, rhesus monkeys, and marmosets), cetaceans (Pacific white-sided dolphins and killer whales), artiodactyls (cows, buffalo, sheep, and goats), pinnipeds (spotted seals and walruses), and rodents (mice and rats), was monophyletic with a 100\% ML bootstrap probability (BP) and a 1.00 Bayesian posterior probability (BPP). Manatee and elephant SLAMs, dog and pinipped SLAMs, and cetacean and artiodactyl SLAMs formed single clades, each with a 100\% BP and a 1.00 BPP value, respectively.

Morbillivirus phylogeny based on MV H protein sequences reflected the host grouping, except for MV. CDV (dogs, Baikal seals) and PDV (seals), and PMV (porpoises) and DMV (dolphins), respectively, formed single clades each with 100\% BP and 1.00 BPP support (Figure 2(b)). The monophyletic lineage of MV (human) (100\% BP and $1.00 \mathrm{BPP})$ was within the grouping of ruminant viruses, RPV (cow) and PPRV (sheep and goat), with $100 \%$ BP and 1.00 BPP. These phylogenetic trees indicated that SLAMs and viral H proteins roughly coevolved. However, the monophyletic lineage of MV and the ruminant viruses RPV and PPRV suggested that human MV may have originated from ancestral RPV in cattle by acquiring a binding affinity for human SLAM, as proposed in a previous report based on the morbillivirus $P$ gene [9] 
(a)

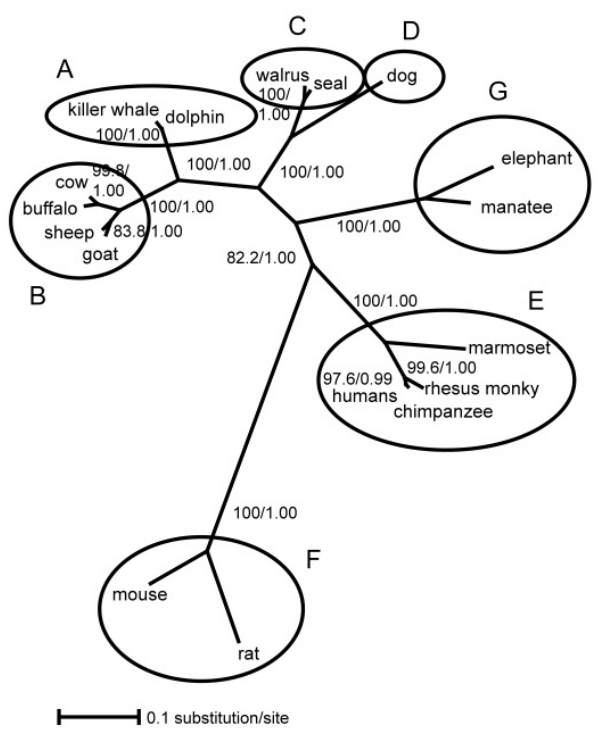

(b)

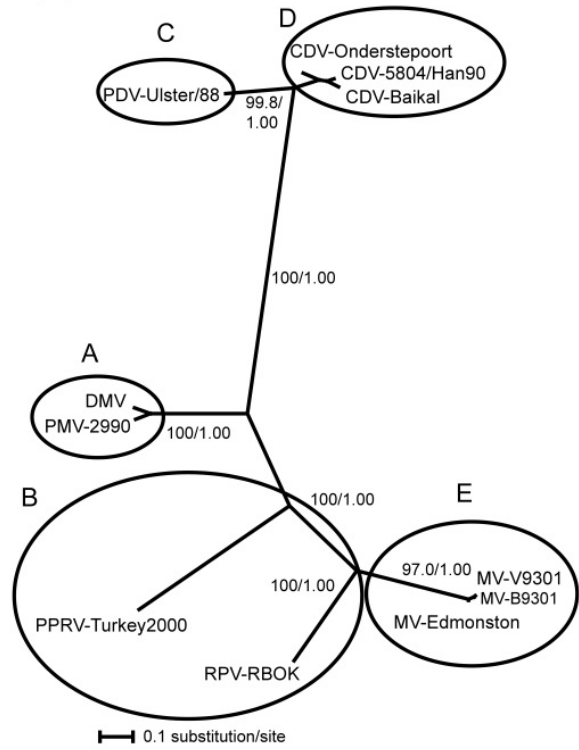

ML analyses were performed using PhyML [72], and an input tree was generated using BIONJ with the JTT model [73] along with amino acid substitution that incorporated invariable sites and used a discrete gamma distribution (eight categories) (JTT $+\mathrm{I}+\mathrm{G}$ model). Bayesian phylogenetic analyses were conducted using MrBayes version 3.0 within the JTT + I + G model [74]. The ML bootstrap probabilities and BPPs are shown at the nodes. Host animals and the corresponding morbilliviruses are shown as circles with the same alphabetic notations: A, cetaceans; B, artiodactyla; C, pinnipeds; D, dogs; E, primates; F, rodents; and G, manatees and elephants. Morbillivirus has not been identified in rodents $(\mathrm{F})$, or manatees and elephants $(\mathrm{G})$. The following SLAM gene sequences were obtained from the Data Bank of Japan: Pacific white-sided dolphin (AB428366); killer whale (AB428367); spotted seal (AB428368); walrus (AB428369); Indian elephant (AB428370); American manatee (AB428371); human beings (Homo sapiens, NM_003037); chimpanzee (Pan troglodytes, XM_513924); marmoset (Saguinus oedipus, AF257239); Rhesus monkey (Macaca mulatta, XM_001117605); cow (Bos taurus, AF329970); buffalo (Bubalus bubalis, DQ228868); sheep (Ovis aries, NM_001040288); goat (Capra hircus, DQ228869); dog (Canis familaris, AF325357); mouse (Mus musculus, NM_013730); and rat (Rattus norvegicus, XM_001054873). Morbillivirus H protein sequences were obtained as follows: MV Edmonston AIK-C strain (AB046218); MV V9301 strain (AB012948); MV B9301 strain (AB012949); RPV RBOK strain (Z30697); PPRV Turkey 2000 strain (NC_006383); CDV Onderstepoort vaccine strain (AF305419); CDV Baikal seal strain (X84998); CDV 5804/Han90 strain (X85000); PDV Ulster/88 strain (D10371); PMV 2990 strain (AY586537); and DMV (NC_005283). The alignments of the deduced amino acid sequences from these genes were generated using ClustalW version 1.8, inspected visually, and edited manually. This figure was adapted from [71].

Figure 2. Phylogenetic trees of SLAM peptide sequences (a) and morbillivirus H proteins (b).

\subsubsection{Three-dimensional models of marine mammal SLAM extracellular domain}

In order to analyze the binding site for morbillivirus, three-dimensional (3D) models of marine mammal SLAM extracellular domains were generated by homology modeling. Previously, we constructed 3D homology models based on the crystallographic structure of the human NTB-A molecule, a member of the SLAM family, as a template [71,75]. In the present study, we generated a new version of the models by adding the recently determined 
crystal structure information of the bound complex of MV H and marmoset SLAM V [56]. Figure 3 shows the 3D model of the Pacific white-sided dolphin SLAM extracellular domain in a self-ligand form. In the models, the V and C2 domains are shown with rod-like structures, which are both constituted mainly of $\beta$-sheets containing several $\beta$-strands. The cysteine residues appear to be important in forming the basic 3D structures. On the basis of amino acid sequence similarity, this structure is shared with all of the SLAMs examined. The $\mathrm{V}$ domain possesses a two-layered $\beta$-sheet structure, and the front sheets provide an interface for binding with morbilliviruses.

(a)

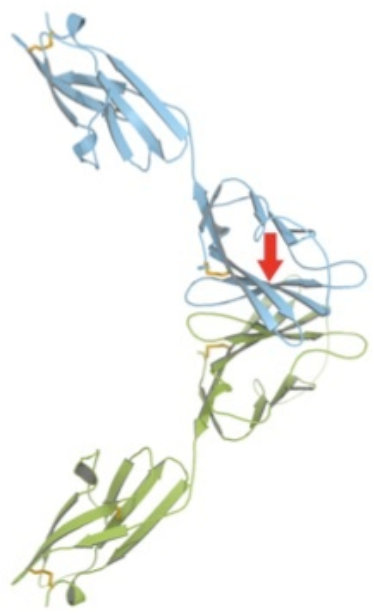

(b)

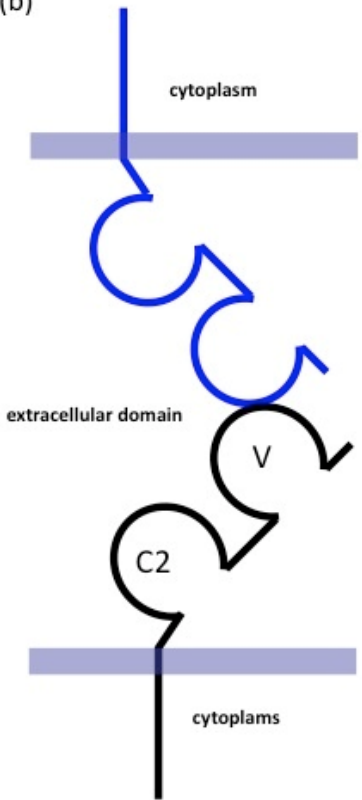

In (a), the blue and green models show respective SLAM extracellular domains forming a homophilic dimer. The $\beta$ strands are indicated by arrows and the disulfide bonds are shown as yellow bars. The thick red arrow indicates the direction of view of the front face of the morbillivirus binding site, as shown in Figure 4. In (b), the blue and black models indicate two SLAM molecules of two adjacent cells, respectively. The Protein Data Bank (PDB) entries for the marmoset SLAM in the complex (3ALW: A-D chains, 3ALX: A-D chains, 3ALZ: B chain; reference [56]) and for human NTB-A (21F7: A-D chains; reference [75]), were used as the template structure. The 3D model was constructed using the MODELLER 9.10 program [76] and visualized using PyMOL 1.4.1 (Schrodinger LLC) and PovRay (Persistence of Vision Pty. Ltd.).

Figure 3. Ribbon diagram of the 3D structure (a) and schematic drawing (b) of the SLAM extracellular domain from the Pacific white-sided dolphin.

Figure 4 shows top views of the front face of the modeled V domains of SLAMs of the spotted seal, Pacific white-sided dolphin, and West Indian manatee. The amino acid residues that have protruding side-chains on their front faces are likely a component of virus binding. We found such qualified 27 amino acid residues; 12 amino acid residues on the $\beta$-strands and 15 residues on loops (Figure 4). In addition, the amino acid residues positioned at 76, and the residues at 127-131 are thought to be important for the binding of 
the virus, because the side-chains of these residues are closely located to those of viral $\mathrm{H}$ protein in a crystal structure of the complex [56]. Particularly, the residues at 127-131 are thought to form an intramolecular $\beta$-sheet with the $\beta$-strand of $\mathrm{MV} \mathrm{H}$ [56]. The overall 3D structures of the interfaces are similar among SLAMs, but several among the total 32 amino acid residues possibly contributing the binding affinity to the virus, differed among the three marine mammals.

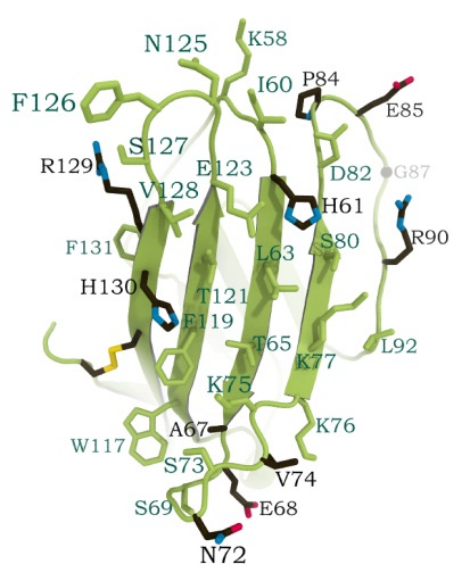

(a)

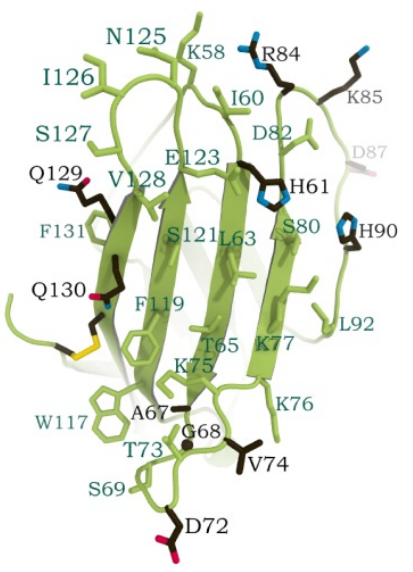

(b)

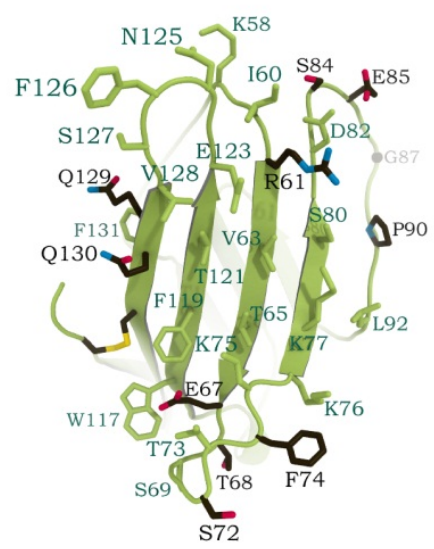

(c)

The interfaces are viewed from the direction shown by the thick red arrow in Figure 3. The amino acid residues that possibly interact with the viral $\mathrm{H}$ protein, are shown with their position numbers. The different amino acid residues among the three mammal SLAMs are indicated in black, and their side-chains are shown with the atoms colored (black for carbons, blue for nitrogens, and red for oxygens). The shared residues among the three are shown in blue. Disulfide bonds are shown in yellow.

Figure 4. Ribbon diagram of the 3D structure models of the SLAM interface for binding morbillivirus from the spotted seal (a), Pacific white-sided dolphin (b), and manatee (c). 


\subsubsection{Prediction of amino acid residues involved in virus binding and host-virus specificity}

To identify amino acid residues that are important for host-virus specificity, we compared the 32 residues with those of land mammal SLAMs (Table 2). The difference in the SLAM interface was only two amino acid residues between seal and dog (Val and Ile at position 74, and Arg and Gln at position 129), between human and marmoset (Leu and Phe at position 119, Val and Ile at position 126, marmoset data not shown), and between cow and sheep (Asp and Gly at position 87, and Arg and His at position 90). This is consistent with the evidence that mass die-offs of Baikal seals and Caspian seals were caused by CDV; marmosets are highly sensitive to MV; and that RPV and PPRV can infect ruminants. It is noted that the identity of these 32 residues between dolphin and cow SLAMs is very high, although they are infected by different morbilliviruses, CMV and RPV, respectively. Four residues are different between the two animals, while eleven and fourteen residues are different between dolphin and seal, and between dolphin and humans, respectively.

\begin{tabular}{|c|c|c|c|c|c|c|c|}
\hline a.a. No. & Seal & Dog & Dolphin & Cow & Sheep & Human & Manatee \\
\hline 58 & $\mathrm{~K}$ & $\mathrm{~K}$ & $\mathrm{~K}$ & $\mathrm{~K}$ & $\mathrm{~K}$ & $\mathrm{~K}$ & $\mathrm{~K}$ \\
\hline 60 & I & I & I & I & I & I & I \\
\hline 61 & $\mathrm{H}$ & $\mathrm{H}$ & $\mathrm{H}$ & $\mathrm{H}$ & $\mathrm{H}$ & $\mathrm{H}$ & $\mathrm{R}^{*}$ \\
\hline 63 & $\mathrm{~L}$ & $\mathrm{~L}$ & $\mathrm{~L}$ & $\mathrm{~L}$ & L & V & V \\
\hline 65 & $\mathrm{~T}$ & $\mathrm{~T}$ & $\mathrm{~T}$ & $\mathrm{~T}$ & $\mathrm{~T}$ & $\mathrm{~T}$ & $\mathrm{~T}$ \\
\hline 67 & $\mathrm{~A}$ & $\mathrm{~A}$ & $\mathrm{~A}$ & $\mathrm{~A}$ & $\mathrm{~A}$ & $\mathrm{~A}$ & $E^{*}$ \\
\hline 68 & $\mathrm{E}$ & $E$ & $\mathrm{G}^{*}$ & $E$ & $E$ & $\mathrm{~K}^{*}$ & $\mathrm{~T}^{*}$ \\
\hline 69 & $S$ & $S$ & $S$ & $S$ & $S$ & $S$ & $S$ \\
\hline 72 & $\mathrm{~N}$ & $\mathrm{~N}$ & D & D & D & $\mathrm{N}$ & S \\
\hline 73 & $S$ & $S$ & $\mathrm{~T}$ & $\mathrm{~T}$ & $\mathrm{~T}$ & $S$ & $\mathrm{~T}$ \\
\hline 74 & $\mathrm{~V}$ & I & $\mathrm{V}$ & $\mathrm{V}$ & $\mathrm{V}$ & $\mathrm{V}$ & $\mathrm{F}$ \\
\hline 75 & $\mathrm{~K}$ & $\mathrm{~K}$ & $\mathrm{~K}$ & $\mathrm{~K}$ & $\mathrm{~K}$ & $E^{*}$ & $\mathrm{~K}$ \\
\hline 76 & $\mathrm{~K}$ & K & K & K & K & $\mathrm{N}^{*}$ & K \\
\hline 77 & K & $\mathrm{K}$ & K & K & $\mathrm{K}$ & K & $\mathrm{K}$ \\
\hline 80 & $S$ & S & $S$ & $S$ & $S$ & $S$ & S \\
\hline 82 & $\mathrm{D}$ & $\mathrm{D}$ & $\mathrm{D}$ & D & D & $\mathrm{D}$ & D \\
\hline 84 & $\mathrm{P}$ & $\mathrm{P}$ & $\mathrm{R}$ & $\mathrm{R}$ & $\mathrm{R}$ & $S$ & $S$ \\
\hline 85 & $E$ & $E$ & $\mathrm{~K}$ & $\mathrm{~K}$ & $\mathrm{~K}$ & $E$ & $E$ \\
\hline 87 & $\mathrm{G}$ & G & $\mathrm{D}$ & $\mathrm{D}$ & $G$ & G & G \\
\hline 90 & $\mathrm{R}$ & $\mathrm{R}$ & $\mathrm{H}$ & $\mathrm{R}$ & $\mathrm{H}$ & $\mathrm{R}$ & $\mathrm{P}^{*}$ \\
\hline 92 & $\mathrm{~L}$ & $\mathrm{~L}$ & $\mathrm{~L}$ & $\mathrm{~L}$ & $\mathrm{~L}$ & $\mathrm{~L}$ & $\mathrm{~L}$ \\
\hline 117 & $W$ & $W$ & W & $W$ & $W$ & W & $W$ \\
\hline 119 & $F$ & $\mathrm{~F}$ & $\mathrm{~F}$ & F & F & $\mathrm{L}$ & F \\
\hline 121 & $\mathrm{~T}$ & $\mathrm{~T}$ & $S$ & $S$ & $S$ & $\mathrm{~T}$ & $\mathrm{~T}$ \\
\hline 123 & $\mathrm{E}$ & E & $E$ & $E$ & E & $E$ & $E$ \\
\hline
\end{tabular}




\begin{tabular}{|l|l|l|l|l|l|l|l|}
\hline a.a. No. & Seal & Dog & Dolphin & Cow & Sheep & Human & Manatee \\
\hline 125 & N & N & N & N & N & N & N \\
\hline 126 & F & F & I & V & V & V & F \\
\hline 127 & S & S & S & S & S & S & S \\
\hline 128 & V & V & V & V & V & V & V \\
\hline 129 & $\mathrm{R}^{*}$ & Q & Q & Q & Q & Q & Q \\
\hline 130 & H & H & Q & H & H & R & Q \\
\hline 131 & F & F & F & F & F & F & F \\
\hline Viruses & PDV, & CDV & CMV & $\begin{array}{l}\text { RPV, } \\
\text { PPRV }\end{array}$ & $\begin{array}{l}\text { PPRV, } \\
\text { RPV }\end{array}$ & MV & None \\
\hline
\end{tabular}

The residue position, which varies among animals, is shaded. The light- and dark-shaded boxes indicate a variation in chemically (charge, hydrophilicity, etc.) similar or different residues. The asterisk indicates the specific residue with a chemical change for the animal SLAM. See the legend of Figure 2 for the animal names and accession numbers of the amino acid sequences used in this table.

Table 2. Amino acid residues on the SLAM interface possibly involved in regulating the binding and specificity of morbilliviruses.

Among the 32 residue positions, variations in amino acids were found at 18 positions (Table 2 , light and dark shading). At six positions (63,73,74,119,121, and 126), the changes are between chemically similar residues (light-shaded boxes in Table 2) and these do not seem to markedly affect binding with the viruses. On the other hand, the variations at the other twelve residue positions $(61,67,68,72,75,76,84,85,87,90,129$, and 130; dark-shaded boxes in Table 2) occur in amino acids with chemically different characteristics. In particular, the variations among amino acids with opposite charge may significantly alter the affinity for viruses (positions 68,75, and 85). The twelve amino acid residues are thought to be important in determining host-virus specificity. Almost of the twelve residues are located in the edge region of the interface. This may indicate that residues located in the central region of the interface play an important role in virus entry itself, rather than in host-virus specificity. Alternatively, they may be essential for a primary immunological function.

A detailed binding assay using surface plasmon resonance analysis was carried out between human SLAM mutants and the MV H protein [56,57]. The respective changes in the residues from H61, E123, and R130 of the human SLAM interface to serine residues completely abolished the binding ability to the MV H protein. In crystallographic analysis, R130 was suggested to form an intramolecular salt bridge with E75 [56]. Only human SLAM possesses these two residues on the interface. As shown in Table 2, K68, a strong positively charged residue, is also specific for human SLAM. These facts suggest that they are key residues for MV infection. On the other hand, H61 and E123 are conserved in all mammals, except for R61 of manatees, suggesting that these residues play a crucial role in viral infection, rather than in host-virus specificity.

Although a detailed analysis of SLAM-virus interaction has not been conducted in systems other than the human SLAM-MV complex, animal-specific residues can be seen in Table 2 . For example, the markedly specific residue set R84-K85-D87-H90 is found in dolphin. These 
residues are located spatially near each other in the 3D homology model of the interface (Figure 4). To clarify the influence of the changes in the charge, electrostatic potentials on the surface of SLAM interfaces of the three marine mammals, are shown in Figure 5. It can be seen that the zone constituted by the residues at positions $84,85,87$, and 90 are different among the SLAM interfaces of three marine mammals.

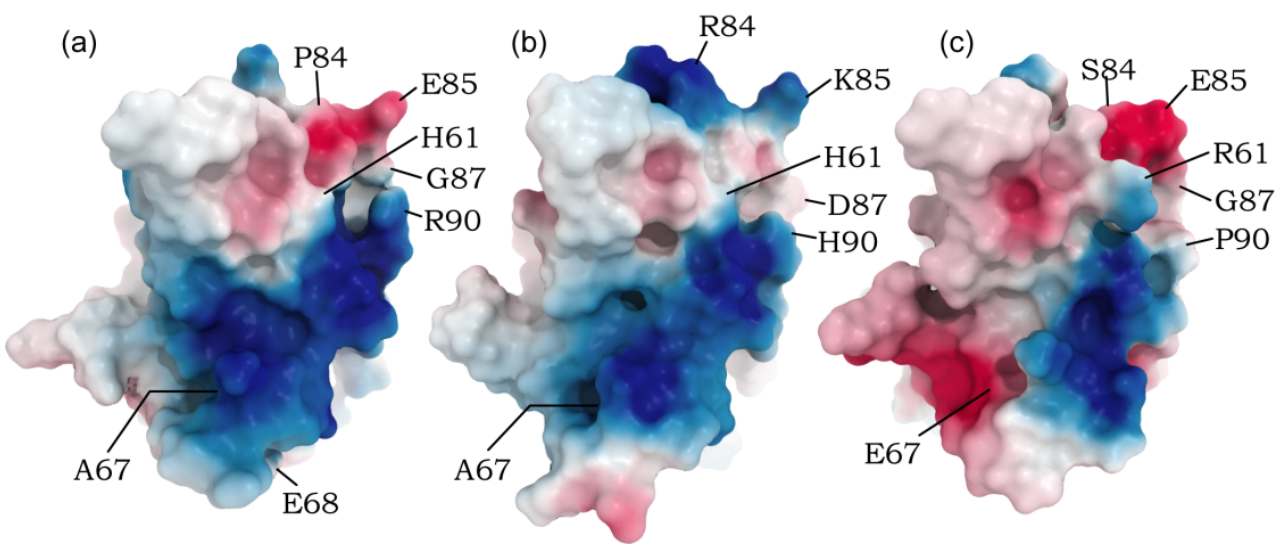

Electrostatic potential was calculated using DelPhi v.4 [77,78]. Positively and negatively charged surfaces are colored blue and red, respectively.

Figure 5. Electrostatic potential on the surface of the SLAM interfaces with morbilliviruses deduced from the 3D homology model structures of the SLAM interfaces from the spotted seal (a), Pacific whitesided dolphin (b), and manatee (c).

The amino acid residues at positions 67 and 68 are also highly variable among the three interfaces (Table 2). The manatee-specific residue E67 appears to contribute greatly to the formation of the negatively charged zone (Figure 5). The manatee SLAM has two another specific residues, R61 and P90, which induce an acquisition of stronger positive charge or a loss of positive charge on the interface (Table 2, Figure 4). These findings suggest that if there is a morbillivirus for the sirenians, it has the $\mathrm{H}$ protein with a very different SLAM binding interface.

Crystallographic analysis of the complex of MV H and marmoset SLAM V unexpectedly showed two different potentially tetramic configurations, form I and form II [56]. Residue N53 is located at the interface only in form II. Its replacement mutant changing to Q53 showed a reduction in molecular masses, meaning the loss of glycosylation, and an unexpected increase in MV entry into human cells. The reason for this is not fully understood. However, because only primate and manatee SLAMs possess residue N53, it may also be involved in host-virus specificity. 


\section{Risk assessment of morbillivirus infection based on SLAM interface structures}

Human beings have a long history of diseases caused by morbilliviruses, which introduced devastating contagious diseases to humans and domestic animals. Since Jenner's seminal discovery of the concept of immunity and vaccines, vaccines against various pathogens have been developed. By virtue of that great endeavor, an effective vaccine against measles is now available [79,80]. It has reduced measles deaths worldwide by $74 \%$ between 2000 and 2010 (from 535,300 to 139,300), although measles is still a threat for children in developing countries [81]. Rinderpest induced by RPV, one of the oldest recorded livestock plagues, has been actually eradicated by the success of the Global Rinderpest Eradication Programme [82-84]. Thus, numerous efforts at eradication have achieved the control of human and domesticated animal diseases. Similar control of morbillivirus infections in wild animals will be one of the most important issues in the field of veterinary medicine in the 21st century. Marine mammals have large geographical ranges in the oceans. For example, baleen whales are known to migrate seasonally from the equator to the polar seas, indicating that they may be a dynamic vector for infectious diseases. In addition, recent global climate change may alter the ecology of marine mammals, such as their habitats, migration patterns, food, and behavior, and may increase opportunities for contact among previously geographically separate mammalian populations. These alterations may increase the possibility of viral transmission and the likelihood of outbreaks in susceptible mammalian populations.

In viral infection, disease incidence, and transmission, several factors in host cells play a key role. In addition, ecological factors such as animal distribution, population structure and size, and behavior are decisive factors in actual infection. In the present study, we used a new approach to assess the potential infectivity of morbilliviruses based on receptor structure predictions. The residues on the interface of the SLAM V domain probably contribute to virus binding, and some residues among them are key for host-virus specificities. The analysis of these residues on 3D models of the SLAM receptor is useful for estimating the risk of morbillivirus infection in wild animals. This approach is applicable to animals for which no information on infection and disease. For the animals, it is possible to predict potential infection with known morbilliviruses. This may reveal possible infection spectra of morbilliviruses and suggest which mammals are reservoirs that maintain the viruses and how these viruses spread among wild mammals in nature.

Control of infectious diseases in wild animals is very difficult. However, even though we cannot stop outbreaks from occurring in nature, information on the potential sensitivity of wild mammals against a virus may minimize the damage or prevent the spread of disease by such means as artificial transportation. Because marine mammals are positioned at the top of oceanic food chain, a decrease in marine mammal populations will affect marine ecosystems. We believe that the present study contributes to the conservation of marine mammals and their ecosystems. 


\section{Conclusion}

Morbillivirus, a member of the family Paramyxoviridae, is a causative agent of mass mortalities of marine mammals. To date, four virus species, MV, RPV, PPRV, and CDV have been identified in land mammals, and two virus species, PDV and CMV, have been identified in seals and cetaceans, respectively [4,47]. The notable biological feature of morbillivirus is its high level of host specificity. The cellular receptor for a virus is a major determinant of its host specificity and tissue tropism. SLAM is the principal cellular receptor for morbilliviruses allowing entry and propagation [18,19]. SLAM contains two immunoglobulin-like domains, the $\mathrm{V}$ and $\mathrm{C} 2$ domains, in the extracellular region. The morbillivirus $\mathrm{H}$ protein binds to the $\mathrm{V}$ domain on the target cells, which triggers viral infection [53] To assess the host-virus specificity of morbillivirus in marine mammals, we determined the complete nucleotide sequences of SLAM from five species belonging to cetaceans, pinippeds, and sirenians, and generated 3D homology models. The results showed that the overall structures are similar in the mammals examined. We found 32 amino acid residues on the interface of SLAM V domain that are potentially involved in the interaction with viruses. Among them, a set of 18 amino acid residues is important for morbillivirus binding because some residues in the set differ among the mammal groups, which are susceptible to different morbillivirus species. A change in some residues in the set may cause an electrostatic change on the interface surface. These amino acid residues are thought to be important for host-virus specificity.

Analysis of these residues on the interfaces of SLAMs will be useful to assess the risk of morbillivirus infection in wild animals. Recent climate change may increase the opportunities for new contacts among wild mammals and for the transmission of viruses. In the present study, we propose a new approach to assess the viral sensitivities of wild mammals by analyzing the host receptors. This approach will contribute to the conservation of wildlife including marine mammals and ecosystems.

\section{Author details}

Kazue Ohishi* and Tadashi Maruyama

Japan Agency for Marine-Earth Science and Technology (JAMSTEC), Yokosuka, Japan

Rintaro Suzuki

Protein Research Unit, National Institute of Agrobiological Science, Tsukuba, Japan

\section{Acknowledgement}

The authors are grateful for the cooperation of the Yokohama Hakkeijima Sea-Paradise Aquamuseum (Yokohama), Kamogawa Sea World (Chiba), Churaumi Aquarium (Okinawa), and Kanazawa Zoo (Yokohama).

${ }^{*}$ Corresponding Author 


\section{References}

[1] Dierauf AL, Gulland FMD. CRC Handbook of Marine Mammal Medicine: Health, Disease, and Rehabilitation. Florida: CRC Press;2001.

[2] Barrett T, Blixenkrone-Møller M, Di Guardo G, Doming M, Duignan P, Hall A, Mamaev L, Osterhaus ADME. Morbilliviruses in Aquatic Mammals: Report on Round Table Discussion. Veterinary Microbiology 1995;44(5) 261-265.

[3] Di Guardo G; Marruchella, G; Agrimi U, Kennedy S. Morbillivirus Infections in Aquatic Mammals: A Brief Overview. Journal of Veterinary Medicine Series A, Physiology, Pathology Clinical Medicine 2005;52(2) 88-93.

[4] Griffin DE. Measles Virus, In: Knipe DM, Howley PM. (eds.) Field's Virology. Philadelphia: Lippincott Williams \& Wilkins;2001. p1401-1441.

[5] Mahy BWJ, Barrett T, Evans S, Anderson EC, Bostock CJ. Characterization of a Seal Morbillivirus. Nature 1988;336(6195) 115.

[6] Osterhaus AD, Vedder EJ. Identification of Virus Causing Recent Seal Deaths. Nature 1988;335(6185) 20.

[7] Kennedy S, Smyth JA, Cush PF, McCullough SJ, Allan GM, McQuaid S. Viral Distemper Now Found in Porpoises. Nature 1988a;336(6194) 21.

[8] Domingo M, Ferrer L, Pumaorola, M, Marco A, Plana J, Kennedy S, McAliskey M, Rima BK. Morbillivirus in Dolphins. Nature 1990;348(6296) 21.

[9] Barrett T, Visser IK, Mamaev L, Van Bressem MF, Osterhaus ADME. Dolphin and Porpoise Morbillivirus Are Genetically Distinct from Phocine Distemper Virus. Virology 1993;193(2) 1010-1012.

[10] Bolt G, Blixen Krone-Moller M, Gottschalck E, Wishaupt RGA, Welsh MJ, Earle JAP, Rima BK. Nucleotide and Deduced Amino Acid Sequences of the Matrix (M) and Fusion (F) Protein Genes of Cetacean Morbilliviruses Isolated from a Porpoise and a Dolphin. Virus Research 1994;34(3) 291-304.

[11] Diallo A., Barrett T, Barbron M, Subbarao SM, Taylor WPDifferentiation of Rinderpest and Peste des Petits Ruminants Viruses Using Specific cDNA Clones. Journal of Virological Methods 1989;23(2) 127-136.

[12] Anderson EC, Hassan A, Barrett T, Anderson J. Observation on the Pathogenicity for Sheep and Goats and the Transmissibility of the Strain of Virus Isolated during the Rinderpest Outbreak in Sri Lanka in 1987. Veterinary Microbiology 1990;21(4) 309-318.

[13] Grachev MA, Kumarev VP, Mamaev LV, Zorin VL, Baranova LV, Denikina NN, Belikov SI, Petrov EA, Kolesnik VS, Kolesnik RS, Dorofeev VM, Beim AM, Kudelin, VN, Nagieva FG, Sidorov, VN. Distemper Virus in Baikal Seals. Nature 1989;338(6212) 209.

[14] Appel MJG, Yates R.A, Foly Gl, Bernstein JJ, Santinelli S, Spelman LH, Miller LD, Arp LH, Anderson M, Barr M, Pearce-Kelling S, Summers BA. Canine Distemper Epizootic in Lions, Tigers, and Leopards in North America. Journal of Veterinary Diagonosis Investigation 1994;6(3) 277-288. 
[15] Roelke-Parker ME, Munson L, Packer C, Kock R, Cleaveland, SM, Carpenter M, O'Brien SJ, Pospischil, A Hofman-Lehmann, R Lutz, H Mwamengele GL, Mgasa MN, Machange GA, Summers BA, Appel MJ. A Canine Distemper Virus Epidemic in Serengeti Lions (Panthera leo). Nature 1996;379(6564) 441-445.

[16] Duignan PJ, House C, Walsh MT, Campbell T, Bossart GD, Duffy N, Fernandes PJ, Rima BK, Wright S, Geraci JR. Morbillivirus Infection in Manatees. Marine Mammal Science 1995;11(4) 441-451.

[17] Grant RJ, Kelley KL, Maruniak JE, Garcia-Maruniak, A, Barrett T, Manire CA, Romero $\mathrm{CH}$. Expression from Baculovirus and Serological Reactivity of the Nucelocapsid Protein of Dolphin Morbillivirus. Veterinary Microbiology 2010;143(2-4) 384-388.

[18] Tatsuo H, Ono N, Tanaka K, Yanagi Y. SLAM (CDw150) Is a Cellular Receptor for Measles Virus. Nature 2000;406(6789) 893-897.

[19] Tatsuo H, Ono N, Yanagi Y. Morbilliviruses Use Signaling Lymphocyte Activation Molecules (CD150) as Cellular Receptors. Journal of Virology 2001;75(13) 5842-5850.

[20] Cocks BG, Chang CJ, Carballido JM, Yssel H, de Vries JE, Aversa G. A Novel Receptor Involved in T-Cell Activation. Nature 1995;376(6537) 260-263.

[21] Schwartzberg PL, Mueller KL, Qi H, Cannons JL. SLAM Receptors and SAP Influence Lymphocyte Interactions, Development and Function. Nature Reviews Immunology 2009; 9(1) 39-46.

[22] Veillette A. SLAM-Family Receptors: Immune Regulators with or without SAP-Family Adaptors. Cold Spring Harbor Perspectives in Biology 2010;2(3) a002469.

[23] Kiel MJ, Yilmaz OH, Iwashita T, Tilmaz OH, Terhosrt C, Morrison SJ. SLAM Family Receptors Distinguish Hematopoietic Stem and Progenitor Cells and Reveal Endothelial Niches for Stem Cells. Cell 2005;121(7) 1109-1121.

[24] Kennedy S, Smyth JA, McCullough SJ, Allan GM, McNeilly F, McQuaid S. Confirmation of Cause of Recent Seal Deaths. Nature 1988b;335(6189) 404,

[25] Jensen T, van de Bildt M, Dietz HH, Andersen TH, Hammer AS, Kuiken T, Osterhaus A. Another Phocine Distemper Outbreak in Europe. Science 2002;297( 5579) 209.

[26] Muller G, Wohlsein P, Beineke A, Haas L, Greiser-Wilke I, Siebert U, Fonfara S, Harder T, Stede M, Gruber AD, Baumgartner W. Phocine Distemper in German Seals, 2002. Emerging Infectious Diseases 2004;10(4) 723-725.

[27] Barrett T, Crowthe J, Osterhaus ADME, Subbarao SM, Groen J, Haas I, Mamaev IV, Titenko AM, Visser IKG, Bostock CJ. Molecular and Serological Studies on the Recent Seal Virus Epizootics in Europe and Siberia. Science of the Total Environment 1992;115(1-2) 117-132.

[28] Mamaev LV, Denikina NN, Belikov SI, Volchkov VE, Visser IKG, Fleming M, Kai C, Harder TC, Liess B, Osterhaus ADME, Barrett T. Characterisation of Morbillivirus Isolated from Lake Baikal Seals (Phoca sibirica). Veterinary Microbiology 1995;44(2-4) 251-259. 
[29] Mamaev LV, Visser IK, Belikov SI, Denikina NN, Harder T, Goatley L, Rima B, Edginton B, Osterhaus AD, Barrett T. Canine Distemper Virus in Lake Baikal Seals (Phoca sibirica). Veterinary Record 1996;138(18) 437-439.

[30] Visser IKG, Kumarev VP, Orvell C, Vries PDE, Broeders HWJ, van de Bildt MWJ, Grosen J, Teppema JS, Burger MC, UytdeHaag FGCM, Osterhaus, ADME. Comparison of Two Morbilliviruses Isolated from Seals during Outbreaks of Distemper in Northwest Europe and Siberia. Archives of Virology 1990;111(3-4) 149-164.

[31] Visser IKG, van der Heijden RWJ, van der Bildt MWG, Kenter MJH, Orvell C, Osterhaus ADME. Fusion Protein Gene Nucleotide Similarities, Shared Antigenic Sites and Phylogenetic Analysis Suggest that Phocid Distemper Virus Type 2 and Canine Distemper Virus Belong to the Same Virus Entity. Journal of General Virology 1993b;74(9) 1989-1994.

[32] Forsyth MA, Kennedy S, Wilson S, Eybatov T, Barrett T. Canine Distemper Virus in a Caspian Seal. Veterinary Record 1998;143(24) 662-664,

[33] Kennedy S, Kuiken T, Jepson PD, Deaville R, Forsyth M, Barrett T, van de Bildt MW, Osterhaus AD, Eybatov T, Duck C, Kydyrmanov A, Mitrofanov I, Wilson S. Mass dieoff of Caspian seals caused by canine distemper virus. Emerging Infectious Diseases 2000;6(6) 637-639.

[34] Visser KG, van Bressem M-E, de Swart RL, van de Bildt MWG, Vos HW, van der Heijden J, Saliki JT, Orvell C, Kitching P, Barrett T, Osterhaus ADME. Characterisation of Morbilliviruses Isolated from Dolphins and Harbour Porpoises in Europe. Journal of General Virology 1993a ;74(4) 631-641.

[35] Di Guardo G, Agrimi U, Morelli L, Cardeti G, Terracciano G, Kennedy S. Post Mortem Investigations on Cetaceans Found Stranded on the Coasts of Italy between 1990 and 1993. Veterinary Record 1995;136(17) 439-452.

[36] Lipscomb TP, Schulman FY, Moffett D, Kennedy S. Morbilliviral Disease in Atlantic Bottlenose Dolphins (Tursiops truncatus) from the 1987-1988 Epizootic. Journal of Wildlife Diseases 1994;30(4) 567-571.

[37] Krafft A, Lichy JH, Lipscomb TP, Klaunberg BA, Kennedy S, Taubernberger JK. Postmortem Diagonosis of Morbillivirus Infection in Bottlenose Dolphins (Tursiops truncatus) in the Atlantic and Gulf of Mexico Epizootics by Polymerase Chain ReactionBased Assay. Journal of Wildlife Diseases1995;3(7) 410-415.

[38] Taubenberger JK, Tsai M, Krafft AE, Lichy JH, Reid AH, Schulman FY, Lipscomb TP. Two Morbilliviruses Implicated in Bottlenose Dolphin Epizootics. Emerging Infectious Diseases1996;2(3) 213-216.

[39] Lipscomb TP, Kennedy S, Moffett D, Krafft A, Klaunberg BA, Lichy JH, Regan GT, Worthy GA, Taubenberger JK. Morbilliviral Epizootic in Bottlenose Dolphins of the Gulf of Mexico. Journal of Veterinary Diagnosis Investigation 1996;8(3) 283-290, .

[40] Osterhaus A, Groen J, Niesters H, van de Bildt M, Martina B, Vedder L, Vos J, van Egmond H, Abou-Sidi B, Barham ME. Morbillivirus in Monk Seal Mass Mortality. Nature 1997;388(6645) 838-839. 
[41] Hernández M, Robinson I, Aguilar A, González LM, López-Jurado LF, Reyero MI, Cacho E, Franco J, López-Rodas V. Costas E. Did Algal Toxins Cause Monk Seal Mortality? Nature 1998;393(6680) 28-29.

[42] Black EL. Epidemiology of Paramyxoviridae, In: Kingsbury D. (ed.) The Paramyxoviruses. New York; Plenum Press, New York 1991. p509-536.

[43] Osterhaus ADME, Groen J, Uytdehaag FGCM, Visser IKG, Vedder EJ, Crowther J, Bostock CJ. Morbillivirus Infections in European Seals before 1988. Veterinary Record 1989; 125(12) 326.

[44] Henderson GA, Trudgett A, Lyons C, Reonald K. Demonstration of Antibodies in Archival Sera from Canadian Seals Reactive with a European Isolate of Phocine Distemper Virus. Science of the Total Environment 1992;115( 1-2) 93-98.

[45] Ross PR, Visser IKG, Broeders HW, van de Bildt MW, Bowen WD, Osterhaus AD. Antibodies to Phocine Distemper Virus in Canadian Seals. Veterinary Record 1992;130(23) 514-516.

[46] Dietz R, Ansen CT, Have P, Heide-Jorgensen M-P. Clue to Seal Epizootic? Nature 1989; 338(6217) 627.

[47] Barrett T, Rima BK. Molecular Biology of Morbillivirus Diseases of Marine Mammals. In: Pfeiffer CJ. (ed.) Molecular and Cell Biology of Marine Mammals. Florida: Krieger Publishing Company; 2006. P161-172.

[48] Blixenkrone-Moller MV, Svansson V, Have P, Botner A, Nielsen J. Infection Studies in Mink with Seal-Derived Morbillivirus. Archives of Virology 1989;106(1-2) 165-170.

[49] Veillette A, Cruz-Munoz ME, Zhong MC. SLAM Family Receptors and SAP-Related Adaptors: Matters Arising. Trends in Immunology, 2006;27(5) 228-234.

[50] Sayos J, Wu C, Morra M, Wang N, Zhang X, Allen D, van Schaik S, Notarangelo L, Geha R, Roncarolo MG, Oettgen H, De Vries JE, Aversa G, Terhorst C. The X-Linked Lymphoproliferative-Disease Gene Product SAP Regulates Signals Induced through the Co-Receptor SLAM. Nature, 1998;395(6701) 462-469.

[51] Morra M, Howie D, Grande MS, Sayos J, Wang N, Wu C, Engel P, Terhorst C. X-Linked Lymphoproliferative Disease: A Progressive Immunodeficiency. Annual Reviews Immunology, 2011;19 657-682.

[52] Mavaddat N, Mason DW, Aikinson PD, Evans EJ, Gilbert RJ, Stuart DI, Fennelly JA, Barclay AN, Davis SJ, Brown MH. Signaling Lymphocytic Activation Molecule (CDw150) Is Homophilic but Self-Associates with Very Low Affinity. Journal of Biological Chemistry 2000; 275(36), 28100-28109.

[53] Ono N, Tatsuo H, Tanaka K, Minagawa H, Yanagi Y. V Domain of Human SLAM (CDw150) Is Essential for Its Function as a Measles Virus Receptor. Journal of Virology 2001;75(4) 1594-1600.

[54] Hashiguchi T, Kajikawa M, Maita N, Takeda M, Kuroki K, Sasaki K, Kohda D, Yanagi Y, Maenaka K. Crystal Structure of Measles Virus Hemagglutinin Provides Insight into Effective Vaccines. Proceedings of the National Academy of Sciences of the USA 2007;104(49) 19535-19540. 
[55] Navaratnarajah CK, Leonard VH, Cattaneo R. Measles Virus Glycoprotein Complex Assembly, Receptor Attachment, and Cell Entry. Current Topics of Microbiology and Immunology 2009;329 59-76.

[56] Hashiguchi T, Ose T, Kubota M, Maita N, Kamishikiryo J, Maenaka K, Yanagi Y. Structure of the Measles Virus Hemagglutinin Bound to Its Cellular Receptor SLAM. Nature Structural \& Molecular Biology 2011a;18(2) 135-141.

[57] Hashiguchi T, Maenaka K, Yanagi Y. Measles Virus Hemagglutinin: Structural Insights into Cell Entry and Measles Vaccine. Frontiers in Microbiology 2011b; 2, Article 247.

[58] Plemper RK, Brindley MA, Iorio RM. Structural and Mechanistic Studies of Measles Virus Illuminate Paramyxovirus Entry. PLoS Pathogens 2011;7(6), e1002058

[59] Dorig RE, Marcil A, Chopra A, Richardson CD. The Human CD46 Molecule Is a Receptor for Measles Virus (Edmonston Strain). Cell 1993;75(2) 295-305.

[60] Naniche D, Varior-Krishnan G, Cervoni F, Wild TF, Rossi B, Rabourdin-Combe C, Gerlier D. Human Membrane Cofactor Protein (CD46) Acts as a Cellular Receptor for Measles Virus. Journal of Virology 1993;67(10) 6025-6032.

[61] Enders JE, Peebles TC. Propagation in Tissue Cultures of Cytopathogenic Agents from Patients with Measles. Proceeding of the Society of Experimental Biological Medicine $1954 ; 86(2)$ 277-286.

[62] Katz SL, Milovanovic MV, Enders JF. Propagation of Measles Virus in Cultures of Chick Embryo Cells. Proceeding of the Society of Experimental Biological Medicine 1958;97(1) 23-29.

[63] Kobune F, Sakata H, Sugimura A. Marmoset Lymphoblastoid Cells as a Sensitive Host for Isolation of Measles Virus. Journal of Virology 1990;64(2) 700-705.

[64] Muhlebach MD, Mateo M, Sinn PL, Prufer S, Uhlig KM, Leonard VH, Navaratnarajah CK, Frenzke M, Wong XX, Sawatsky B, Ramachandran S, McCray PB, Cichutek K, von Messling V, Lopez M, Cattaneo R. Adherens Junction Protein Nectin-4 Is the Epithelial Receptor for Measles Virus. Nature 2011;480(7378) 530-533.

[65] Noyce RS, Bondre DG, Ha MN, Lin L-T, Sisson G, Tsao M-S, Richardson CD. Tumor Cell Marker PVR4 (nectin 4) Is an Epithelial Cell Receptor for Measles Virus. PLoS Pathology 2011; 7(8):e1002240.

[66] Sakaguchi M, Yoshikawa Y, Yamanouchi K, Sata T, Nagashima K, Takeda K. Growth of Measles Virus in Epithelial and Lymphoid Tissues of Cynomolgus Monkeys. Microbiology and Immunology 1986;30(10) 1067-1073.

[67] de Swart RL, Ludlow M, de Witte L, Yanagi Y, van Amerongen G, McQuaid S, Yuksel S, Geijtenbeek TB, Duprex WP, Osterhaus AD. Predominant Infection of CD150+ Lymphocytes and Dendritic Cells during Measles Virus Infection of Macaques. PLoS Pathology 2007;11: e178.

[68] Leonard VH, Sinn PL, Hodge G, Miest T, Devaux P, Oezguen N, Braun W, McCray PB Jr, McChesney MB, Cattaneo R. Measles Virus Bound to Its Epithelial Cell Receptor Remains Virulent in Rhesus Monkeys but Cannot Cross the Airway Epithelium and Is Not Shed. Journal of Clinical Investigation 2008;118(7) 2448-2458. 
[69] Shirogane Y, Takeda M, Tahara M, Ikegame S, Nakamura T, Yanagi Y. EpithelialMesenchymal Transition Abolishes the Susceptibility of Polarized Epithelial Cell Lines to Measles Virus. Journal of Biological Chemistry 2010;285(27) 20882-20890.

[70] Tahara M, Takeda M, Shirogane Y, Hashiguchi, T, Ohno S, Tanagi Y. Measles virus infects both polarized epithelial and immune cells by using distinctive receptor-binding sites on its hemagglutinin. Journal of Virology 2008;82(5) 4630-4637.

[71] Ohishi K, Ando A, Suzuki R, Takishita K, Kawato M, Katsumata E, Ohtsu D, Okutsu K, Tokutake K, Miyahara H, Nakamura H, Murayama T, Maruyama T. Host-Virus Specificity of Morbilliviruses Predicted by Structural Modeling of the Marine Mammal SLAM, a Receptor. Comparative Immunology, Microbiology and Infectious Diseases, 2010;33(3) 227-241.

[72] Guindon S, Gascuel O. A Simple, Fast, and Accurate Algorithm to Estimate Large Phylogenies by Maximum Likelihood. Systematic Biology, 2003; 52(5) 696-704.

[73] Jones DT, Taylor WR, Thornton JM. The Rapid Generation of Mutation Data Matrices from Protein Sequences. Computer Applications in the Biosciences 1992;8, 275-282.

[74] Ronquist F, Huelsenbeck JP. MrBayes 3: Bayesian Phylogenetic Inference under Mixed Models. Bioinformatics 2003;19(22) 1572-1574.

[75] Cao E, Ramagopal UA, Fedorov A, Fedorov E, Yan Q, Lary JW, Col, JL, Nathenson SG, Almo SC NTB-A Receptor Crystal Structure: Insights into Homophilic Interactions in the Signaling Lymphocytic Activation Molecule Receptor Family. Immunity, 2006;25(4) 559-570.

[76] Sali A, Blundell TL. Comparative Protein Modelling by Satisfaction of Spatial Restraints. Journal of Molecular Biology 1993;234(3) 779-815.

[77] Rocchia W, Alexov E, Honig B. Extending the Applicability of the Nonlinear PoissonBoltzmann Equation: Multiple Dielectric Constants and Multivalent Ions. Journal of Physiology Chemistry B 2001;105 6507-6514.

[78] Rocchia W, Sridharan S, Nicholls A, Alexov E, Chiabrera A, Honig B. Rapid Grid-Based Construction of the Molecular Surface and the Use of Induced Surface Charge to Calculate Reaction Field Energies: Applications to the Molecular Systems and Geometric Objects. Journal of Computer Chemistry 2002;23(1) 128-137.

[79] Katz SL. John F. Enders and measles virus vaccine - a reminiscence, Current Topics of Microbiology and Immunology, 2009: 329; 3-11.

[80] Strebel PM, Cochi SL, Hoekstra E, Rota PA, Featherstone D, Bellini WJ, Katz SL. Journal of Infectious Diseases, 2011: 204(Suppl 1), 1-3.

[81] WHO Measles mortality reduction, http://www.who.int/immunization/newsroom/measles_rubella/en/index.html (2011)

[82] FAO Global Rinderpest Eradication Programme (GREP). http://www/fao.org/ag/againfo/programmers/en/grep/home.html/ (2011)

[83] OIE No More Death from Rinderpest. http://www.oie.int/for-the-media/pressrelease/detail/article/no-more-deaths-from-rinderpest/ (2011). 
[84] Rweyemamu M, Roder PL, Taylor WP. Chapter 15, Towards the Global Eradication of Rinderpest, In: Taylor WP, Barrett T, Pastoret P-P. (Eds.) Rinderpest and Peste des Petits Ruminants, Virus Plagues of Large and Small Ruminants. New York: pp. 298-22, Academic Press;2005. p298-322. 